\title{
PENYULUHAN PENGHIJAUAN SEMPADAN SUNGAI CILIWUNG DI KELURAHAN SRENGSENG SAWAH KECAMATAN JAGAKARSA JAKARTA SELATAN
}

\author{
Hinijati Widjaja ${ }^{1}$, Rini Fitri ${ }^{2}$, Reza Fauzi ${ }^{3}$ \\ 123 Dosen Program Studi Arsitektur Lanskap Fakultas Arsitektur Lanskap dan \\ Teknologi Lingkungan Universitas Trisakti \\ Email: hinijati@trisakti.ac.id, rini.fitri@trisakti.ac.id, reezzaafau@gmail.com
}

\begin{abstract}
ABSTRAK
Kegiatan PKM ini bertema Penyuluhan Penghijauan Sempadan Sungai Ciliwung di Kelurahan Srengseng Sawah Kecamatan Jagakarsa Jakarta Selatan. Tujuan kegiatan pengabdian kepada masyarakat ini adalah: 1) sebagai wujud pelaksanaan Tri Dharma Perguruan Tinggi oleh dosen Prodi. Arsitektur Lanskap Fakultas Arsitektur Lanskap dan Teknologi Lingkungan Universitas Trisakti, dan 2) untuk menerapkan pengetahuan dan praktik penghijauan lingkungan di Sempadan Sungai Ciliwung. Pelaksanaan kegiatan PKM ini dilaksanakan di Sempadan Sungai Ciliwung Kelurahan Srengseng Sawah Kecamatan Jagakarsa Jakarta Selatan. Penyuluhan dilakukan dengan memberikan ceramah dan praktik menanam pohon tanaman di sepanjang Sempadan Sungai Ciliwung. Berdasarkan hasil pelaksanaan kegiatan PKM dengan tema Penyuluhan Penghijauan Sempadan Sungai Ciliwung di Kelurahan Srengseng Sawah Kecamatan Jagakarsa Jakarta Selatan, disimpulkan bahwa masyarakat yang berada di wilayah Sempadan Sungai Ciliwung Kelurahan Srengseng Sawah Kecamatan Jagakarsa Jakarta Selatan, semakin memahami dan merasakan manfaat dari penyuluhan penghijauan Sempadan Sungai Ciliwung. Kegiatan pengabdian kepada masyarakat ini sangat sesuai dengan kondisi Sempadan Sungai Ciliwung yang rawan erosi dan longsor.
\end{abstract}

Kata Kunci: ciliwung jakarta, penghijauan, penyuluhan, sempadan sungai

\begin{abstract}
A community service activity themed Greening Counseling of the Ciliwung River Riparian Area in Srengseng Sawah Village, Jagakarsa District, South Jakarta. The purpose of community service is (1) as a form of implementing the Three Pillars of Higher Education by lecturers of the Study Program of Landscape Architecture, Faculty of Landscape Architecture and Environmental Technology, University Trisakti, (2) to apply knowledge and practices of counseling greening the environment on the Ciliwung river riparian area. This community service activity was implemented at the Ciliwung river riparian area, Srengseng Sawah Village, Jagakarsa District, South Jakarta. Counseling is carried out by giving lectures and practicing planting trees along the Ciliwung river riparian area. Based on the results of the implementation of activities community service with the theme of the Greening Consouling of the Ciliwung River Riparian Area in Srengseng Sawah Village, Jagakarsa District, South Jakarta, it was concluded that those people living in the Ciliwung river riparian area, Srengseng Sawah Village, Jagakarsa District, South Jakarta, increasingly understand and feel the benefits of reforestation counseling. Ciliwung river riparian area. The Community service activities in the form of counseling about reforestation on the Ciliwung river riparian area, Srengseng Sawah Village, Jagakarsa District, South Jakarta are very
\end{abstract}


suitable for the conditions of the Ciliwung river riparian area, which are prone to erosion and landslides.

Key Words : ciliwung jakarta, counseling, reforestation, riparian area

\section{PENDAHULUAN}

Penghijauan merupakan kegiatan memelihara, memulihkan dan meningkatkan fungsi lahan secara optimal sesuai peruntukannya. Gerakan penghijauan yang dilakukan masyarakat sepanjang Sempadan Sungai Ciliwung Kelurahan Srengseng Sawah Kecamatan Jagakarsa Jakarta Selatan merupakan upaya untuk memperbaiki kondisi lingkungan yang rusak akibat aktivitas masyarakat dan lahan terdegradasi. Masyarakat Indonesia masih belum banyak memiliki kesadaran tentang penghijauan lingkungan, bahkan sebagian hanya menyalahkan pihak-pihak berwenang dalam menanganinya jika sudah terjadi banjir, lahan kritis dan tanah longsor (Purwanto, 2021).

Pelaksanaan penghijauan dilakukan melalui penanaman berbagai jenis vegetasi berdasarkan fungsinya untuk memperbaiki wilayah hutan yang rusak, lahan tererosi dan longsor di daerah sempadan sungai. Penghijauan memiliki beberapa manfaat, diantaranya: 1) secara orologis, mampu mengikat akar pohon dengan tanah menjadi satu kesatuan yang kuat sehingga dapat mencegah erosi, 2) secara ekologi, menjadikan lingkungan semakin baik dan seimbang antara struktur buatan manusia dan struktur alam, 3) secara hidrologis, dapat menyerap air hujan, sehingga daerah yang vegetasi lebat akan tersedia air yang cukup untuk kebutuhannya, 4) secara klimatologis, banyaknya pohon akan menurunkan suhu setempat, sehingga udara disekitarnya menjadi sejuk, segar dan nyaman, dan 5) secara edukatif, adanya beragam pohon yang ditanam dilingkungan sekitar merupakan laboratorium alam, karena dapat dimanfaatkan sebagai tempat belajar mengenal tanaman dari berbagai aspek (Harryanto., et al., 2017).

Sempadan sungai merupakan garis batas pengamanan sungai yang membatasi agar tidak mendirikan bangunan liar di pinggir sungai dan pemeliharaan sungai, lebar sempadan berbeda di tiap sungai antara perkotaan dan pedesaan. Daerah sempadan sungai menurut Peraturan Menteri Pekerjaan Umum No. 63/PRT/1993, menyatakan bahwa daerah sepanjang kanan kiri sungai termasuk sungai buatan yang mempunyai fungsi penting 
untuk mempertahankan kelestarian fungsi sungai. Peraturan Pemerintah Republik Indonesia No. 38 Tahun 2011, menyatakan bahwa sempadan sungai berfungsi sebagai ruang penyangga antara ekosistem sungai dan daratan, agar fungsi sungai dan kegiatan manusia tidak saling terganggu. Maryono (2014), menyatakan bahwa pengelolaan sempadan sungai melibatkan nilai sosial, ekonomi dan fisik. Maka, sasaran pengabdian kepada masyarakat di Kelurahan Srengseng Sawah Kecamatan Jagakarsa Jakarta Selatan, diharapkan agar masyarakat dapat memahami manfaat penghijauan sempadan sungai serta masyarakat turut berpartisipasi aktif dalam menanam bibit tanaman untuk memelihara keberlanjutan Sempadan Sungai Ciliwung.

Tujuan pelaksanaan kegiatan PKM dengan tema Penyuluhan Penghijauan Sempadan Sungai Ciliwung di Kelurahan Srengseng Sawah Kecamatan Jagakarsa Jakarta Selatan, yaitu: 1) sebagai wujud pelaksanaan Tri Dharma Perguruan Tinggi oleh dosen Prodi. Arsitektur Lanskap Fakultas Arsitektur Lanskap dan Teknologi Lingkungan Universitas Trisakti; dan 2) untuk menerapkan pengetahuan dan praktik penghijauan lingkungan di Sempadan Sungai Ciliwung. Adapun target luaran yang dihasilkan dari pelaksanaan kegiatan penyuluhan berupa publikasi pada jurnal pengabdian kepada masyarakat berISSN, baik cetak maupun online.

\section{METODE PELAKSANAAN}

Kegiatan PKM dengan tema Penyuluhan Penghijauan Sempadan Sungai Ciliwung di Kelurahan Srengseng Sawah Kecamatan Jagakarsa Jakarta Selatan dilaksanakan dalam beberapa tahapan, yaitu: 1) mempelajari referensi, 2) pendekatan dengan pihak mitra di lapangan, 3) diskusi mengenai materi yang akan disampaikan kepada masyarakat untuk menumbuhkan kesadaran tentang penghijauan sempadan sungai, dan 4) menjadwalkan waktu pelaksanaan kegiatan penyuluhan yang disepakati pada tanggal 27 s.d 28 Januari 2021. Adapun pelaksanaan kegiatan PKM ini dilaksanakan selama 2 (dua) hari, yaitu pada tanggal 27 s.d 28 Januari 2021, pukul 13.00 Wib s.d selesai. Kegiatan ini diikuti oleh mahasiswa dan TIM dosen PKM Prodi. Arsitektur Lanskap serta masyarakat yang ada di kawasan Sempadan Sungai Ciliwung Kelurahan Srengseng Sawah Kecamatan Jagakarsa Jakarta Selatan. 


\section{HASIL DAN PEMBAHASAN}

Kegiatan pengabdian kepada masyarakat berupa penyuluhan tentang penghijaun pada Sempadan Sungai Ciliwung Kelurahan Srengseng Sawah Kecamatan Jagakarsa Jakarta Selatan, sangat sesuai dengan kondisi Sempadan Sungai Ciliwung yang rawan erosi dan longsor. Kegiatan PKM ini sangat bermanfaat bagi masyarakat yang berdomisili di sepanjang Sampadan Sungai Ciliwung Kelurahan Srengseng Sawah Kecamatan Jagakarsa Jakarta Selatan. Kegiatan PKM tentang penyuluhan penghijauan Sempadan Sungai Ciliwung mendapat dukungan dan sambutan yang sangat antusias dari masyarakat yang berdomisili di sepanjang Sempadan Sungai Ciliwung Kelurahan Srengseng Sawah Kecamatan Jagakarsa Jakarta Selatan.
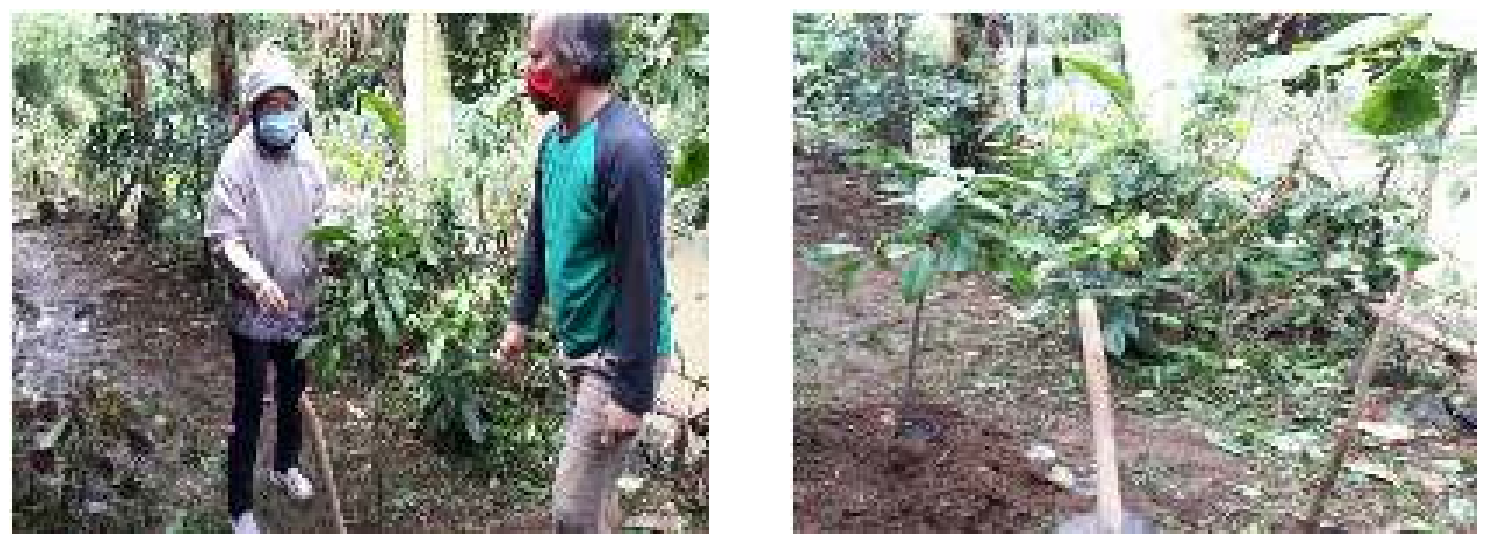

Gambar 1. Kegiatan Penyuluhan dan Penanaman Pohon untuk Penghijauan

Masyarakat yang berada di wilayah Sempadan Sungai Ciliwung Kelurahan Srengseng Sawah Kecamatan Jagakarsa Jakarta Selatan, semakin memahami dan merasakan manfaat dari penyuluhan penghijauan Sempadan Sungai. Masyarakat di kawasan Sempadan Sungai Kelurahan Srengseng Sawah Kecamatan Jagakarsa Jakarta Selatan sangat bersemangat menanam tanaman tahunan untuk penghijauan sempadan sungai.

Kegiatan penyampaian materi penyuluhan mengenai penghijauan bagi masyarakat Sepandang Sungai Ciliwung Kelurahan Srengseng Sawah Kecamatan Jagakarsa Jakarta Selatan menggunakan bahasa sederhana dan mudah dipahami masyarakat setempat. Materi kegiatan penyuluhan tersebut sangat tepat dan menjadikan masyarakat semakin paham bagaimana cara merawat sempadan sungai, melalui partisipasi langsung untuk menanam tanaman tahunan di lingkungan tempat tinggalnya di sepanjang Sempadan 
Sungai Ciliwung Kelurahan Srengseng Sawah Kecamatan Jagakarsa Jakarta Selatan. Selain itu, masyarakat mendapatkan sumbangan bibit tanaman dari Prodi Arsitektur Lanskap Fakultas Arsitektur Lanskap dan Teknologi Lingkungan Universitas Trisakti.
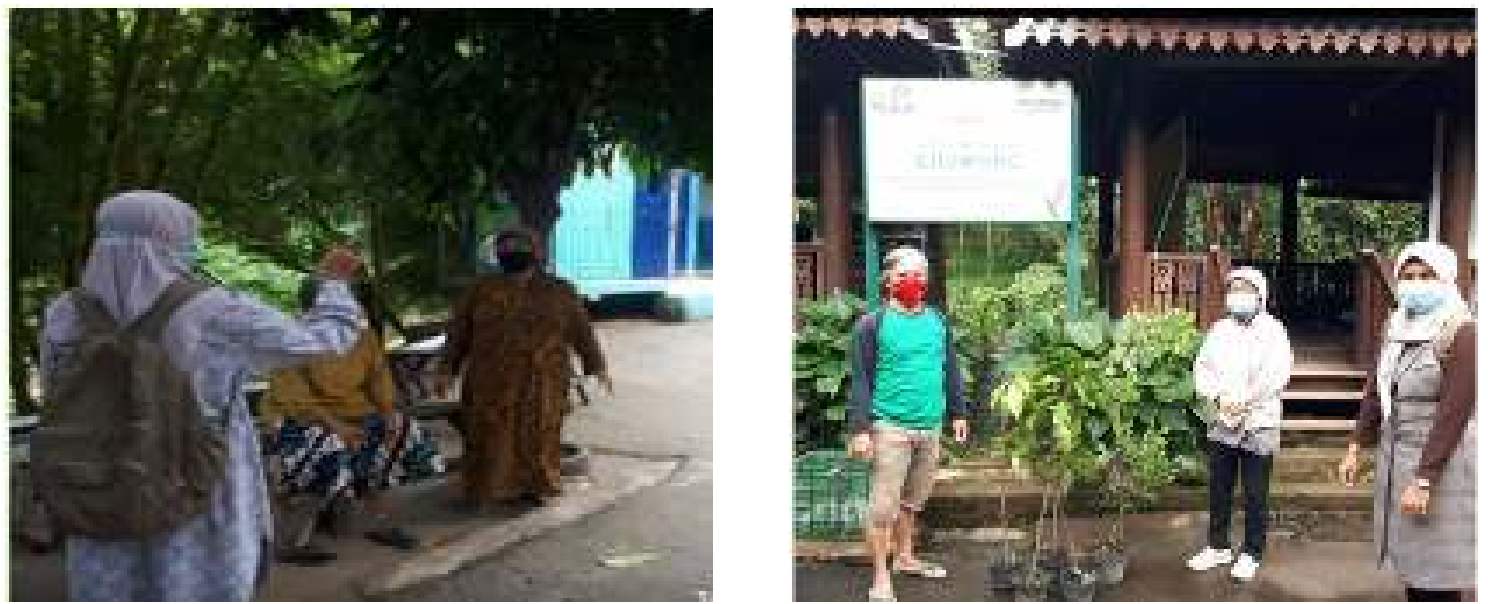

Gambar 2. Kegiatan Penyuluhan dan Penyerahan Bibit Tanaman Penghijauan

\section{KESIMPULAN DAN SARAN}

Berdasarkan hasil pelaksanaan kegiatan PKM berupa penyuluhan mengenai penghijauan bagi masyarakat di sekitar Sempadan Sungai Ciliwung Kelurahan Srengseng Sawah Kecamatan Jagakarsa Jakarta Selatan disimpulkan bahwa penyuluhan penghijauan ini mendapat tanggapan postitif tentang manfaat penghijauan Sempadan Sungai Ciliwung Kelurahan Srengseng Sawah Kecamatan Jagakarsa Jakarta Selatan. Terlihat partisipasi dan kepedulian masyarakat sangat tinggi untuk menanam tanaman tahunan di Sempadan Sungai Ciliwung Kelurahan Srengseng Sawah Kecamatan Jagakarsa Jakarta Selatan.

Adapun saran yang perlu disampaikan setelah melakukan PKM ini hendaknya pihak pemerintahan Kecamatan Jagakarsa dan Kelurahan Srengseng Sawah, lebih meningkatkan penyuluhan tentang penghijaun untuk kelestarian Sempadan Sungai Ciliwung Kelurahan Srengseng Sawah Kecamatan Jagakarsa Jakarta Selatan.

\section{UCAPAN TERIMA KASIH}

Penulis mengucapkan terima kasih kepada Rektor Universitas Trisakti atas kepercayaan dan dana yang diberikan pada Pengabdian kepada Masyarakat (PKM) Mono semester 
ganjil tahun akademik 2020/2021 sebagai bentuk pelaksanaan Tridharma Perguruan Tinggi.

\section{REFERENSI}

Harryanto, R., dkk. 2017. Gerakan Penghijauan DAS Citarum Hulu di Desa Cikoneng Kecamatan Cileunyi Kabupaten Bandung. Dharmakary, 6 (2): 78-82.

Maryono, A. 2014. Pengelolaan Kawasan Sempadan Sungai dengan Pendekatan Integral: Peraturan, Kelembagaan, Tata Ruang, Sosial, Morfologi, Ekologi, Hidrologi dan Keteknikan. Yogyakarta: Gadjah Mada University Press.

Peraturan Menteri Pekerjaan Umum No. 63/PRT/1993 tentang Garis Sempadan Sungai.

Peraturan Pemerintah Republik Indonesia No. 38 Tahun 2011 tentang Sungai.

Purwanto. 2021. Penyuluhan tentang Penghijauan Lingkungan di Desa Klodran Kecamatan Colomadu Kabupaten Karanganyar. Budimas, 3(1): 149-154. 